\title{
ROMANIAN
}

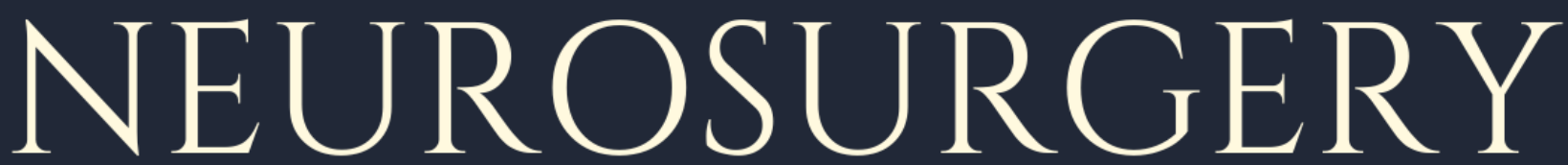

Vol. XXXIV | No. 4 December 2020

\section{Dorsolumbar angiolipoma. A rare case report and review of literature}

\author{
Surendra Kumar Gupta, \\ Anuj Chhabra, \\ Hanuman Kumar Prajapati, \\ Faran Ahmad
}




\section{Dorsolumbar angiolipoma. A rare case report and review of literature}

\section{Surendra Kumar Gupta ${ }^{1}$, Anuj Chhabra ${ }^{2}$, Hanuman Kumar Prajapati ${ }^{3}$, Faran Ahmad ${ }^{4}$}

\author{
${ }^{1}$ MCh Neurosurgery. Assistant professor. Department of \\ Neurosurgery, AlIMS Raipur, INDIA \\ 2 Assistant Professor. Department of Neurosurgery. Kalpana Chawla \\ Government Medical College, Karnal, Haryana, INDIA \\ ${ }^{3}$ MCh Neurosurgery. Assistant Professor. Department of \\ Neurosurgery, Uttar Pradesh University of Medical Sciences, Saifai, \\ Etawah, INDIA \\ 4 DNB Neurosurgery. Senior Resident. Department of Neurosurgery, \\ Dr Ram Manohar Lohia Institute of Medical Sciences, Lucknow, INDIA
}

\section{ABSTRACT}

A 55-year-old female was presented with complaints of tingling sensations of the bilateral lower limb with spastic paraplegia for last one year. Her pre-operative contrast MRI study of Dorsolumbar Spine was suggestive of extradural angiolipoma. She underwent D11, D12 and L1 Laminectomy and a mildly vascular yellowish globular extradural mass was found which was excised completely and dural decompression was achieved. Post-operatively, the patient's neurologic symptoms improved.

Conclusion: Spinal angiolipoma is considered a rare benign entity which emulates malignancy. It should be included as a differential diagnosis of the spinal epidural tumour with fat component and a high degree of vascularisation. surgical removal of this epidural tumour through a proper and comprehensive approach provides complete and permanent recovery.

\section{INTRODUCTION}

Spinal angiolipoma and angiomyolipoma are rare tumors, there incidence was noted only $0.14 \%$ of all tumors of the spinal axis. It is difficult to distinguish them from spinal lipoma, as they are found mainly in adults. They are localised almost exclusively in the dorsal epidural space of the thoracic spine [4]. They are not associated with any malformation. These lesions usually show no tendency to involve the surrounding tissue although some may show infiltrative process into the bony compartment of the vertebral column [5, 14].

We are reporting a rare case of angiolipoma of the dorsolumbar spine in a 55-year-old female patient that was diagnosed by pathological examination following surgical resection, and discuss the imaging findings of angiolipoma published in literature.

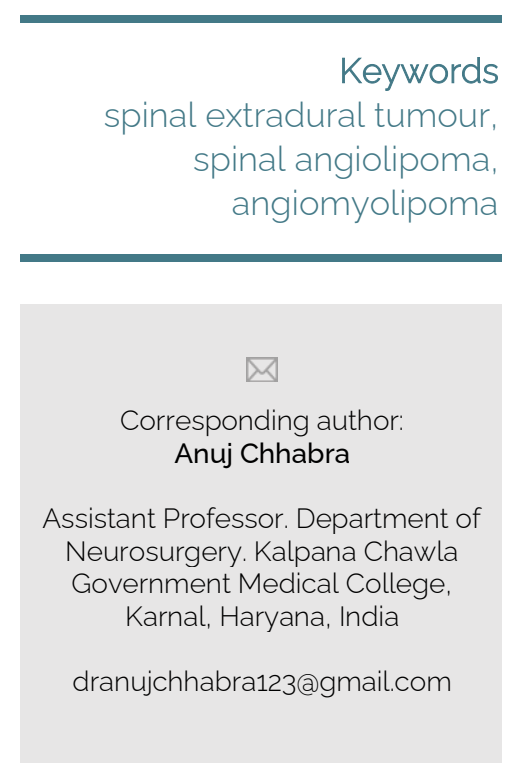

Copyright and usage. This is an Open Access article, distributed under the terms of the Creative Commons Attribution Non-Commercial No Derivatives License (https://creativecommons org/licenses/by-nc-nd/4.0/) which permits noncommercial re-use, distribution, and reproduction in any medium, provided the original work is unaltered and is properly cited

The written permission of the Romanian Society of Neurosurgery must be obtained for commercial re-use or in order to create a derivative work.

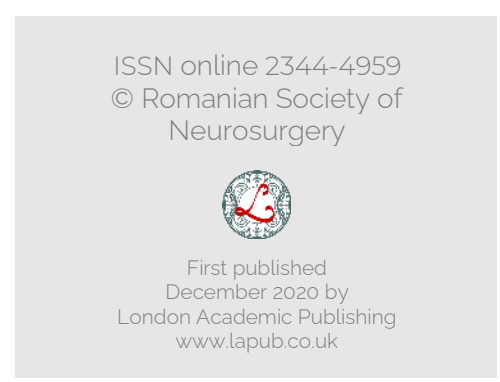




\section{CASE REPORT}

A 55-year-old female were admitted in our hospital with complaints of tingling sensation of bilateral lower limb with spastic paraplegia for last one year.

Her neurological examination was showing paraplegia with diminished sensations over B/L lower limbs. Knee and ankle jerks were exaggerated with significant increase in tone. Her MRI (magnetic resonance imaging) dorsolumbar spine was showing signal of the fat and blood vessels. The fatty content was hyperintense on both $\mathrm{T} 1$ - and T2-weighted images (similar to the signal of subcutaneous adipose tissue) and hypointense on fat-suppressed images. The vascular component was hypointense on T1-weighted and hyperintense on T2-weighted, and showed intense enhancement with Gd-DTPA infusion (Figure 1).

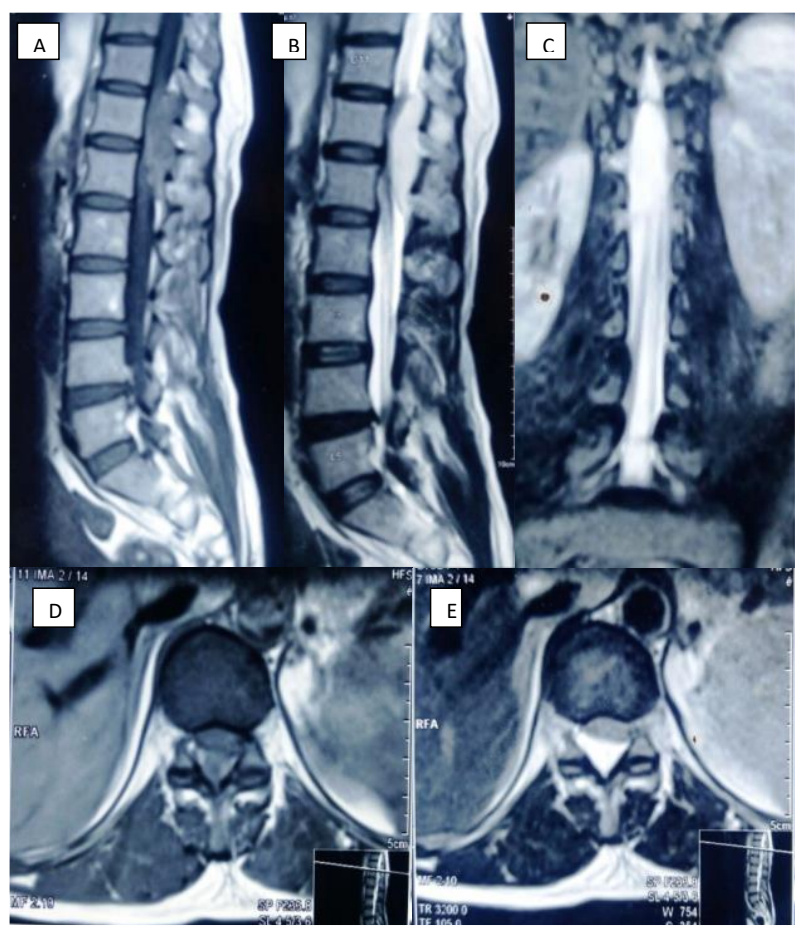

Figure 1. Spindle shaped extradural contrast enhancing on T1W Contrast (1A, D) and hyperintense on T2W (1B,C,E).

She was planned for laminectomy with decompression of cord under general anaesthesia. She underwent D11, D12 and L1 Laminectomy and a mildly vascular yellowish globular extradural mass was found which was excised completely and dural decompression was achieved

On histopathological Examination. Microscopic examination revealed sheets of mature adipocytes arranged in lobules divided by delicate intervening fibrous septae showing numerous thick-walled blood vessels without elastic lamina. No evidence of malignancy was noted, so histopathology diagnosis of angiolipoma was given (Figure 2).
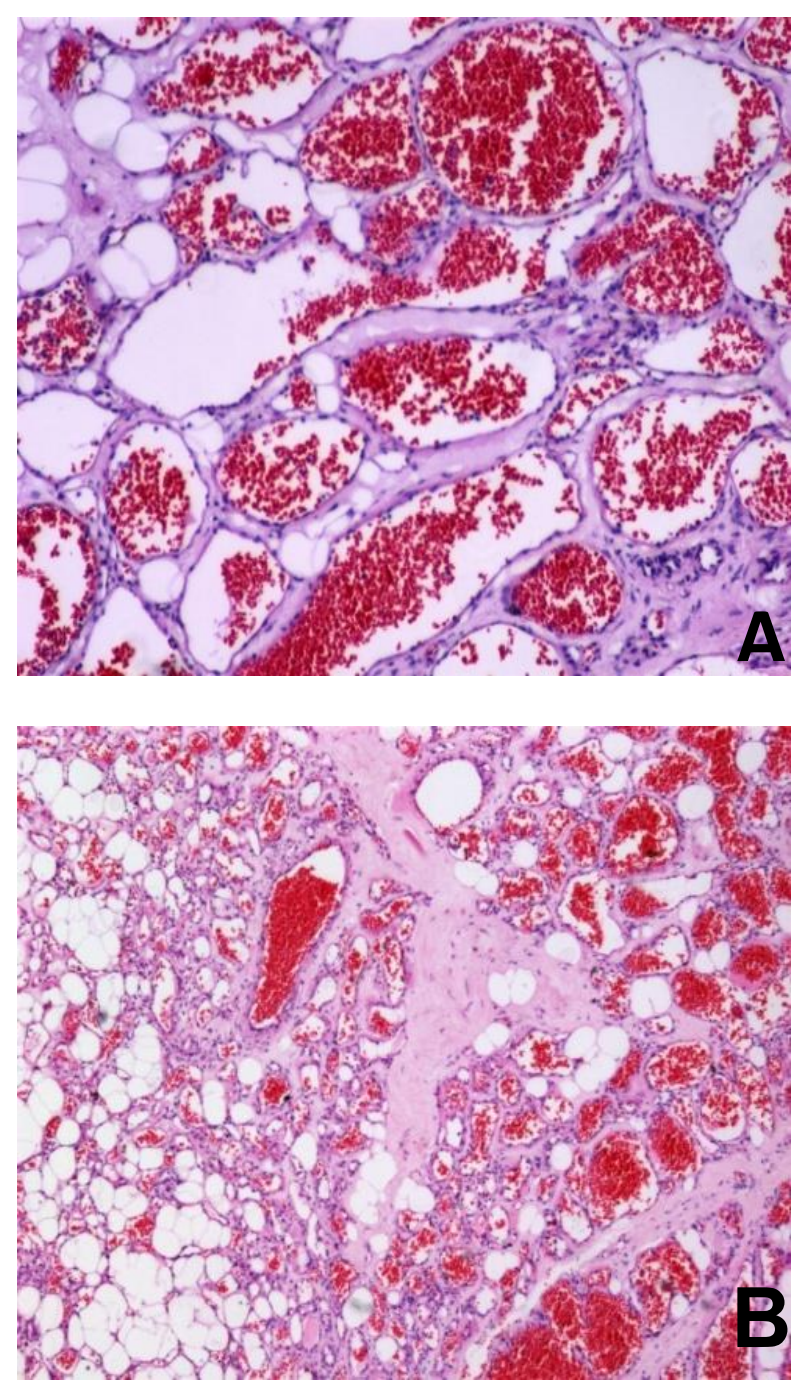

Figure 2. Photomicrographs show mature adipose tissue and proliferated vascular tissue with thin septation and foci of fibrosis (A; H\&E, 100X, B; H\&E, 400X).

Post-operative Course. The patient's neurologic symptoms improved immediately. On second postoperative day, her power in bilateral lower limb improved to $4 / 5$. She was discharged on fifth postoperative day. On two months follow up, no signs of recurrence and neurological deficits were noted.

\section{DISCUSSION}

Howard and Helwig described angiolipoma as one entity in 1960 [7]. They said that the majority of these 
tumors are found in subcutaneous vessel, muscle, bone and kidney and it was noted that they have no tendency to recur after excision. More than 50 cases of spinal angiolipoma and angiomyolipoma have been reported [1-3, 6, 8-11]. After reviewing following clinical and radiologic characteristics were noted:

1) These tumors are occurs in middle aged patients usually;

2) These are mostly located in the dorsal epidural space;

3) They grow in a spindle shape along the spinal canal;

4) They lack the associated malformations; and

5) They are mostly benign and result in a good postoperative outcome.

Most of spinal angiolipomas are found to be nonfiltrating hence complete excision is the rule. In a few reported cases the tumor merges to the extradural fat so that it is difficult to differentiate tumor from the fat [12].

The pathogenesis of Angiomyolipoma (AML) and Angiolipoma is not clear. Two major theories have been given previously regarding the pathogenesis. One is that primitive pluripotent mesenchyme cells (which provides a common origin to adipose, smooth muscle, and vascular endothelial elements) are developed into tumor by ill-defined stimuli (trauma or other causes). Another theory is that the tumor is a congenital malformation or true hamartoma [7].

It was noted in most patients with spinal AML and angiolipoma that they have complaints of neurological symptoms related to spinal cord compression, such as weakness of the extremities and abnormal sensation below the level of lesion [3]. It was observed that there exists a relationship between pregnancy and accelerated onset of neurologic symptoms in several cases of epidural spinal angiolipoma [13].

For radiological assessment of spinal AML and angiolipoma, previously conventional radiograph, myelography, or CT were used for the purpose of preoperative diagnosis. Recently in such cases MRI were employed. Both spinal AML and angiolipoma appear as elliptical shaped soft tissue mass with heterogeneous marked enhancement at epidural space of thoracic spine. Fat component with high signal intensity on T1-weighted image is often visualized in cases of spinal angiolipoma [8]. However, infiltrative properties such as invasion to adjacent bone or extension to perilesional space and ventral location have been mentioned as distinctive features of AML compared to major patterns of angiolipoma according to Sakaida et al [14].

Such kind of lesions includes differential diagnosis of fat-containing tumor (such as lipoma, lipomatosis, and liposarcoma), prominently vascular tumor (such as spinal epidural hemangioma), and other T1-high signal intensity lesion (such as epidural hematoma). Epidural lipoma or lipomatosis is an abnormal accumulation of unencapsulated adipose tissue in the extradural space. Because of their fat components, they also display hyper intensity on T1weighted images and intermediate intensity on T2weighted images [12]. However, they present with typical $Y$ configuration (with circumferentially compressed dural sac) and show no definite contrast enhancement pattern. Well-differentiated liposarcoma is a rare fat-containing tumor of the spinal canal. It frequently has irregular thick-ended septa. It contains regions of hyperintense signal (compared to fat) on T2-weighted images which are rare in spinal AML $[8,12,14]$.

\section{CONCLUSION}

Spinal angiolipoma is considered as rare benign entity which emulates malignancy. A sufficient attempt must be made to reach a correct preoperative diagnosis by using reliable imaging techniques such as MRI. It should be included as a differential diagnosis of spinal epidural tumor with fat component and high degree of vascularisation. It can be believed that surgical removal of this epidural tumor through proper and comprehensive approach provides complete and permanent recovery.

\section{REFERENCES}

1. Anson JA, Cybulski GR, Reyes M. Spinal extradural angiolipoma, A report of two cases and review of the literature.Surg Neurol 1990;34: 173-8.

2. Bender JL,Van Ladinghum JH,Manno NJ.Epidural lipoma producing spinal cord compression:report of two cases.J Neurosurg 1974;41:100-3.

3. Geers C, Lecouvet FE, Behets C, Malghem J, Cosnard G, Lengelé BG. Polygonal deformation of the dural sac in lumbar epidural lipomatosis: anatomic explanation by the presence of meningovertebral ligaments. AJNR Am J Neuᄀroradiol 2003;24:1276-1282.

4. Goldblum JR, Weiss SW, Folpe AL. Enzinger and Weiss's soft tissue tumors. 6th ed. Philadelphia: Elsevier Saunders, 2013:897-899. 
5. Gonzalezz-Crussi F, Enneking WF,Arean VM; Infiltrating angiolipoma.J Bone Joint Surg[Am] 1966;48:1111-23.

6. Griebel RW, Khan M,Rozdilski B. Spinal extradural angiolipoma: A case report and literature review.Spine 1986;11: 47-8.

7. Howard WR,Helwig EB. Angiolipoma.Arch Derm(Chicago)1960; 82:924-33.

8. Hu S, Hu CH, Hu XY, Wang XM, Dai H, Fang XM, et al. MRI features of spinal epidural angiolipomas. Korean J Radiol 2013;14:810-817.

9. Kuroda $S, A$ be $H$, Akino $M$, et al. Infiltrating spinal angiolipoma causing myelopathy: Case report. Neurosurgery 1990;27:315-8.

10. Padovani R, Tongnetti F, Speranza S,et al.Spinal extrathecal hemangiolipomas: Report of two cases and review of the literature.Neurosurgery 1982;11:674-7.

11. Pearson J, Stellar S, Feigin I. Angiomyolipoma: Iong term cure following a radical approach to malignant appearing benign intraspinal tumor:Report of three cases.J Neurosurg 1970;33: 466-70.

12. Provenzale JM, McLendon RE. Spinal angiolipomas: MR features. AJNR Am J Neuroradiol 1996;17:713-719

13. Rubin G, Gornish M, Sandbank J, et al. Spinal Extradural angiolipoma:Case report and review of the literature.Spine 1992;17:719-24.

14. Sakaida H, Waga S, Kojima T, Kubo Y, Matsubara T, Yama $\neg$ moto J. Thoracic spinal angiomyolipoma with extracanal extension to the thoracic cavity. A case report. Spine (Phila Pa 1976) 1998;23:391-39. 